\title{
Jornalismo, sistema artístico e cidade na década de 1950: estudo das Notas de Arte de Aldo Obino no jornal Correio do Povo
}

\section{Journalism, art system and the city in the 1950s: study about Notas de Arte by Aldo Obino in the the newspaper Correio do Povo}

\author{
Cida Golin \\ Doutora em Letras pela PUCRS, Professora do Programa de Pós-Graduação em Comunicação e Informação da Universidade \\ Federal do Rio Grande do Sul (UFRGS). Pesquisadora CNPq. \\ <golin.costa@ufrgs.br>
}

\section{Mariana Sirena}

Jornalista, Mestre em Comunicação e Informação pela Universidade Federal do Rio Grande do Sul (UFRGS). <sirena.mariana@gmail.com>

\section{RESUMO}

Este artigo discute a relação entre jornalismo, sistema artístico e cidade a partir do estudo das Notas de Arte, coluna assinada pelo jornalista Aldo Obino (1913-2007) e veiculada no Correio do Povo, um dos principais jornais de Porto Alegre (RS) no século XX. Considerando que o jornalismo destaca e hierarquiza eventos, sujeitos e espaços do sistema de cultura, reforçando ou tensionando valores da arte e do gosto, esta pesquisa buscou identificar o mapa do circuito artístico da cidade proposto pela coluna na década de 1950. Por meio da análise de 314 textos publicados no período, percebemos que o jornalista fez parte de um coro de exaltação à metrópole. Assumindo a proximidade como principal critério jornalístico, registrou em detalhes a transformação e a institucionalização do sistema de artes; estimulou a participação de jovens artistas e coletivos; e defendeu o intercâmbio com outras capitais como condição decisiva para superar determinadas expressões artísticas e o provincianismo local.

\section{ABSTRACT}

This paper discusses the relationship among journalism, artistic system and the city from the study of Notas de Arte column signed by Aldo Obino (1913-2007) and published in Correio do Povo, a leading newspaper in Porto Alegre (RS) in the twentieth century. Whereas journalism ranks and highlights events, subjects and spaces of the cultural system, reinforcing or tensioning art values, this study sought to identify the artistic circuit map of the city proposed by the column in the 1950s. Through the analysis of 314 texts published in the period, we realized that the journalist was part of a chorus of praise to the metropolis. Assuming proximity as his primary journalistic criteria, he registered in detail the transformation and institutionalization of the artistic system, encouraged the participation of young artists and collectives, and defended exchanges with other capitals as a decisive condition to overcome certain artistic expressions and local provincialism.

Keywords: Cultural journalism. City. Aldo Obino. 
Historicamente, o jornalismo vinculou-se às atividades urbanas e fez das cidades a âncora da maioria de suas narrativas. A cobertura de cultura, desde o início, representou a urbe como espaço de poder e de cultura letrada, fazendo do entorno um critério elementar para o processamento dos conteúdos. Na medida em que explora determinadas espacialidades, o jornalismo é produtor privilegiado de sentidos, oferecendo critérios para interpretar a memória e a cultura citadinas. O presente artigo busca explorar como o jornalismo atua na construção dessas perspectivas, ou mapas, partindo do estudo ${ }^{1}$ de uma experiência significativa da história do jornalismo cultural do Rio Grande do Sul - a coluna Notas de Arte, assinada pelo jornalista Aldo Obino (1913-2007) e publicada no jornal Correio do Povo desde o final dos anos 1930 até 1984. A pesquisa foca a produção textual de Obino sobre artes visuais ao longo da década de 1950, época em que o Correio se firmou como diário hegemônico em âmbito regional. O decênio foi marcado, no Brasil, pela modernização do jornalismo, representada por reformas gráficas, redacionais e administrativas em grandes jornais. Em paralelo ao avanço da urbanização pelo país, o sistema artístico vivia um dinamismo crescente, resultante também dos esforços pela sua institucionalização em capitais como Porto Alegre, São Paulo e Rio de Janeiro.

A fim de identificar os referentes a partir dos quais as Notas de Arte foram construídas, utilizamos a metodologia da análise de conteúdo sobre um corpus de 314 unidades, correspondente aos textos publicados entre 1950 e 1959. Buscamos verificar que lugares, agentes, eventos e valores artísticos emergem da coluna, explorando também conformações do discurso construído pelo jornalista acerca desses elementos. Na medida em que o critério jornalístico da proximidade é hegemônico e marcante na cobertura, realizamos uma aproximação da evolução e transformação do circuito cultural de Porto Alegre nos anos 1950. Assim, apresentamos pistas das relações estabelecidas entre jornalismo, sistema artístico e cidade em um dado momento histórico, e das significações do espaço urbano feitas por Obino².

\footnotetext{
1 A investigação resulta de pesquisa de mestrado desenvolvida no Programa de Pós-graduação em Comunicação e Informação da Universidade Federal do Rio Grande do Sul e integra as atividades do Núcleo de Estudos em Jornalismo e Publicações Culturais do Laboratório de Edição, Cultura e Design (FABICO | UFRGS), registrado no CNPq. Desde 2007, o núcleo desenvolve estudos sistemáticos com o intuito de compreender a lógica do jornalismo em sua relação dinâmica com o sistema cultural e permite conhecer experiências editoriais significativas da história da imprensa no Rio Grande do Sul e no Brasil por meio da análise de publicações e da ação de agentes como jornalistas, editores e críticos.

2 Esta dissertação deu continuidade aos resultados do projeto Memória Cultural, desenvolvido no Museu de Arte do Rio Grande do Sul entre os anos de 2001 e 2002 (Obino, 2002). Uma versão reduzida
} 


\section{Jornalismo: guia e construção da cultura na cidade}

No contexto de crescimento das cidades, no século XIX, surgiram as condições necessárias ao estabelecimento da imprensa como espaço legitimado de reconstrução discursiva do mundo e de significação do tempo presente ${ }^{3}$. Ao assumir a função do relato dos fatos não vivenciados, o jornalismo ancorou-se no território urbano de referência, assimilando a aceleração da vida da cidade e estabelecendo uma nova experiência coletiva temporal a partir de sua periodicidade (Franciscato, 2005).

Nesse momento, o jornal constituiu-se como agente importante na dinâmica da urbe, entendida não apenas como espaço, mas também como estado de espírito (Park, 1973). Lançando para o homem moderno parâmetros de compreensão e apreensão do seu território de circulação, o jornal atuou como mediador ao selecionar e sistematizar informações múltiplas e crescentes, num processo paralelo à edição de guias surgidos no século XVIII ${ }^{4}$. Seguindo a perspectiva de Mouillaud (2002), é possível aproximar o jornal do mapa, já que ele localiza as pessoas no mundo, baliza noções de local, nacional, internacional, de próximo e distante. Esse mapa é condicionado por uma perspectiva oculta, que consiste no olhar construído no contexto da esfera de produção da notícia 5 .

Assim como o jornalismo, a produção cultural desenvolveu-se no contexto urbano e foi potencializada pelo fortalecimento de instituições e foros de reconhecimento. Nas dinâmicas do sistema artístico, o jornalismo atua como instância de divulgação e de análise, aproximando os códigos artísticos de um público amplo. Ao valorizar o evento como acontecimento e marco temporal das

deste artigo, enfocando a questão do gênero coluna, será apresentada no XXXVII Congresso Brasileiro de Ciências da Comunicação, em setembro de 2014.

3 No século XIX, principalmente na Inglaterra e nos Estados Unidos, a alfabetização das massas, que levou à formação de um público leitor, e o surgimento de novas tecnologias de impressão, que permitiu o aumento das tiragens e a industrialização da produção noticiosa, influenciaram na gradativa autonomização do campo jornalístico. No Brasil, foi na década de 1950, época marcada pela metropolização de grandes centros urbanos, que a imprensa se consolidou como um espaço autônomo de enunciação sobre os fatos, alicerçando-se na mítica da objetividade. Algumas transformações no sentido da profissionalização vinham ganhando forma desde o início do século XX, mas apenas nessa época elas encontram condições sociais, econômicas e culturais para se firmar.

4 Os guias surgiram e se desenvolveram principalmente no século XVIII, quando algumas metrópoles europeias cresciam vertiginosamente e produziam muitas informações sobre o próprio espaço (Burke, 2003).

5 Tal aspecto diz respeito ao fato de o jornalismo ser discurso, mediação, e não simples reflexo da realidade. Nesse sentido, assumimos um posicionamento vinculado à concepção construcionista, que considera a notícia como uma construção social, fruto de um processo complexo que envolve ação pessoal, pressões do contexto de produção e critérios estabelecidos no bojo de uma cultura profissional. 
narrativas, oferece um instantâneo concentrado sobre o circuito e propõe uma totalidade até então dispersa: congrega os diversos segmentos culturais e seus agentes em disputa e estabelece hierarquias e valoração estética ao destacar determinados eventos ou silenciar outros. (Golin, Keller e Cardoso, 2012).

Uma das particularidades dessa especialização jornalística é a predisposição, historicamente construída, à avaliação para além da informação. O público busca nas páginas culturais da imprensa não somente a agenda, mas também orientação em relação aos produtos disponíveis, eventos em proeminência e debates existentes (Gadini, 2009). A coluna, gênero híbrido e autoral em que nosso objeto de estudo se enquadra, é um dos mais usuais para tratar de cultura. Espaço jornalístico em que a subjetividade do autor é legitimada pela credibilidade construída ao longo do tempo, a coluna pode agregar gêneros argumentativos marcados pelo estilo pessoal, como a crítica e a crônica (Melo, 2003; Ribeiro, 2007). Esta última tradicionalmente se relaciona com a narrativa cotidiana da cidade e está na origem do jornalismo cultural no Brasil.

\section{Aldo Obino: um assíduo narrador da cultura local}

Podemos situar o perfil de Aldo Obino entre os "homens de letras", os chamados críticos-cronistas dos anos 1940 que oscilavam entre a crônica e o noticiário, entre o cultivo da eloquência e a defesa do impressionismo e do autodidatismo (Süssekind, 2002). Na sua maioria, os críticos diletantes estavam inseridos no contexto de influência francesa na cultura do Brasil. Paulatinamente, a partir dos anos 1950, os padrões culturais norte-americanos se mostraram dominantes em diversos setores da sociedade brasileira, tornandose hegemônicos também na imprensa.

Obino nasceu em 25 de outubro de 2013 em Porto Alegre. Seu pai, João Obino, foi gerente comercial do Correio do Povo por 25 anos. Sempre houve por parte da família o estímulo ao estudo e apreço pela arte: o jornalista e seus quatro irmãos tiveram iniciação em alguma área artística, declamação e desenho e, especialmente, música (Obino, 2002). Em carta escrita em 18 de novembro de 1936 para sua irmã Idalina, que era pianista formada pelo Instituto de Belas Artes (IBA), ele revela seu esforço, mesmo tendo consciência de que não atuaria como músico: "Até hoje cismo de estranhar um companheiro de estudo que eu gastasse dinheiro e esforço em cultivar a Música, sem ter nenhuma intenção de tirar dela proveito material (sic)". No mesmo texto, descreve com entusiasmo as músicas que estava aprendendo, pontuando as descrições com elementos 
contextualizadores das obras. Ele não esconde as dificuldades, como a de tocar sendo acompanhado pelo professor ao piano (Sirena, 2014).

Formado em Direito na década de 1930, dedicou-se ao jornalismo e ao magistério. Lecionou Psicologia e Filosofia, a disciplina que mais apreciava, por 30 anos no Colégio Universitário, atual colégio Júlio de Castilhos, importante instituição pública de ensino de Porto Alegre. Ingressou no Correio do Povo como arquivista em 1934, passando em seguida à redação, assumindo a cobertura de cultura. Sua coluna começou a ser publicada em 1938, contendo tanto notas breves sobre fatos do campo cultural e divulgação de eventos quanto textos mais analíticos acerca de exposições, espetáculos de música, dança, etc.

Periodicamente, Obino elaborava o obituário dos artistas e personalidades da área da cultura. Escrevia com frequência para outras seções do jornal como Editoriais e Colaborações - o ensino era uma das áreas que ele mais explorava nos artigos veiculados nessas páginas, além da filosofia e da cultura em geral. Colaborou nos diários porto-alegrenses A Nação e no Jornal do Comércio, no qual escreveu livre e gratuitamente de 1989 a 1995. No âmbito do ensino, vinculouse à Associação de Professores Católicos do Estado, criada por Armando Pereira Câmara, e participou da Revista Estudos dessa associação.

A coluna Notas de Arte era veiculada diariamente nas páginas do Correio do Povo intituladas Secções, local em que eram distribuídas colunas regulares sobre teatro, cinema, artes e variedades. Foi a partir dos anos 1960 que passou a se focar mais na cobertura de artes plásticas, devido ao ingresso no jornal de outros colaboradores especializados em música e teatro. A partir de 1963, passou a aparecer apenas sob a rubrica Artes, mantendo as mesmas características visuais e de texto. Aldo Obino manteve-se como colunista até 1984, completando praticamente cinco décadas de cobertura cultural na companhia jornalística Caldas Júnior.

A constância de sua presença nos eventos ficou na memória de quem o conheceu. Armando Almeida, artista plástico e ex-diretor do MARGS, por exemplo, ao falar sobre a cena artística de Porto Alegre dos anos 1970, destacou que o jornalista era um dos poucos críticos de arte que registravam praticamente toda a movimentação na área: "sempre andava com um caderninho debaixo do braço, anotava tudo o que via e perguntava muito" (Almeida, 2005). Tal assiduidade resultou na constituição de um amplo arquivo de textos e imagens, ao qual aparentemente recorria para construir os relatos.

Em geral, Obino apresentava cada artista a partir de elementos biográficos, de quantas exposições havia realizado, localizando-o em relação às correntes artísticas. Ele, inclusive, colocava-se no texto, comentando o que já 
havia escrito sobre o sujeito em determinadas ocasiões. Dessa forma, reforçava sua credibilidade para avaliar os acontecimentos e a "evolução" dos trabalhos, levando em conta uma posição privilegiada como testemunha da história da arte que se desenvolvia na cidade. A ancoragem da narrativa em Porto Alegre e o acompanhamento da evolução do circuito artístico local foram aspectos centrais de seu legado textual, que se constituiu em matéria-prima importante para os historiadores da arte no Rio Grande do Sul.

\section{Procedimentos de análise}

Para nos aproximarmos do funcionamento das Notas de Arte na década de 1950, realizamos um levantamento e classificação de todas as colunas que abordavam o tema das artes visuais publicadas ao longo do decênio. A seleção, composta por 314 textos, se constituiu no nosso corpus de pesquisa. Ao longo de seu percurso, Obino organizou e catalogou em pastas um número considerável de textos e documentos, e a sua família permitiu o acesso a esses guardados. Realizamos também visitas ao arquivo histórico Moysés Vellinho, da cidade de Porto Alegre, que abriga a coleção do Correio do Povo, para verificar e confirmar a representatividade do corpus $^{6}$.

A construção do objeto teórico e as definições relativas ao exame dos textos foram pensadas de forma a tornar visível o fato de que as Notas de Arte funcionavam como guias informativos sobre o circuito cultural do qual Obino fazia parte como agente mediador. A opção pela metodologia da análise de conteúdo (Bardin, 1977) deu-se pelas possibilidades de sistematização de um corpus extenso, pela conciliação das leituras correlacionadas dos aspectos quantitativo e qualitativo e, principalmente, pelo foco na articulação entre o texto e o seu contexto histórico de existência ${ }^{7}$. A categorização nos aproximou das relações do sistema artístico da época na medida em que apontou não apenas os referentes imediatos do texto, mas também uma perspectiva global do que ocorreu no período (Golin, Cardoso, Sirena, 2014).

6 Ao consultarmos um mês de publicações de cada ano da segunda metade da década (março de 1955, maio de 1956, julho de 1957, setembro de 1958 e novembro de 1959), constatamos que todos os textos encontrados ao longo desses meses sobre artes plásticas no jornal corresponderam aos que estavam no arquivo pessoal do jornalista. Ainda assim, consideramos uma margem de erro nos resultados em função das possíveis lacunas no conjunto coletado.

7 Como afirmam Leal e Antunes (2011, p. 20), autores que refletem sobre essa metodologia a partir da revisão de Bauer (2002), o interesse da AC "não está no conteúdo de um texto, mas nas características da vida social que se manifestam nos textos". Assim, podemos a partir dela identificar tendências, regularidades e recorrências, levantando dados indicadores de dimensões da vida social e da esfera de produção das mensagens. 
Percebendo que o texto de Aldo Obino remete sempre às informações centrais do jornalismo de matriz informativa, tomamos alguns elementos do lead - um dos símbolos do jornalismo moderno consolidado como modelo narrativo no Brasil durante a década de 1950 - para nomear cada uma das categorias. A técnica norte-americana leva o repórter a responder no início do seu texto às perguntas "quem?" fez "o quê?", "onde?", "quando?", "como?" e "por quê?" Apesar do estilo de Obino estar claramente ligado ao padrão francês de jornalismo, bem mais livre e autoral, as questões "quem?" fez "o quê" e "onde?" eram respondidas em cada um dos seus comentários críticos, de forma a explicitar os agentes, os eventos e os locais expositivos que movimentavam o circuito local. Adaptamos também a questão "como?" a uma categoria: já que um aspecto marcante do jornalismo cultural é o caráter opinativo, incluímos nessa classe os posicionamentos estéticos e ideológicos de Obino que transpareciam nos textos e que refletem valores do sistema das artes.

Dada a amplitude das rubricas escolhidas, elegemos um aspecto para costurar as reflexões, balizando a interpretação do corpus. Levando em conta que a questão territorial é central na constituição do jornalismo e se mostrou estruturante das Notas de Arte desde a primeira leitura do material, escolhemos o olhar do colunista sobre a cidade como fio condutor da análise. Conhecendo os sujeitos, os eventos, os locais e as ideias sobre o que é "boa arte" que circulavam, podemos visualizar a imagem da cidade enquanto circuito de cultura.

\section{Onde?}

O valor-notícia da proximidade se sobressai como principal parâmetro da cobertura de Obino. Das 314 colunas e notas publicadas ao longo da década de 1950, 277 (88,2\%) abordam a produção local ou trazem alguma relação com o universo cultural rio-grandense, seja pela menção da participação de artistas gaúchos em eventos nacionais, seja pela comparação de realidades de outros estados. Um número considerável de textos trata sobre eventos ocorridos na capital gaúcha: 260 (82,8\%) do total.

O jornalista considerava Porto Alegre uma "metrópole" marcada pelo "cosmopolitismo", palavras imbuídas de positividade no contexto da coluna. Como foi mencionado, o seu comentário crítico tinha atributos da crônica, gênero que tradicionalmente toma a vida urbana como matéria-prima. Ele detalhava os endereços das galerias, versava sobre os bairros e enaltecia o centro como núcleo vital da cidade. O pertencimento do autor ao território transparece nas narrativas, ficando evidente na medida em que colocava o pronome possessivo 
"nossa" antes de "metrópole", exaltando a modernização pela qual a capital gaúcha passava em diferentes setores. A cidade projetada pelas Notas de Arte é, primordialmente, espaço da renovação e da movimentação em torno da arte.

Essa tendência à exaltação não era exclusiva de Obino. De acordo com Monteiro (2005), a imprensa local engajara-se na década de 1950 no processo de modernização urbana tanto em termos industriais quanto pelo discurso. O período de crescimento econômico nacional refletiu-se na otimização das condições de produção das empresas jornalísticas, representada pela importação de novos maquinários, pelo aumento da oferta de papel e pelas novas possibilidades de diagramação e impressão. Ao mesmo tempo, imagens da verticalização do centro ganhavam espaço nas páginas dos jornais e revistas. A adoção de padrões arquitetônicos modernistas nas construções, a edificação de grandes obras públicas, a conquista de novas áreas pelo aterramento e a expansão do perímetro urbano eram pautas recorrentes. Em 1958, Obino chamava a atenção para esse cenário na coluna "A progressão de Porto Alegre", de 31 de maio:

A cidade aumenta continuamente a sua população e é a que atualmente mais constrói no país e se expande verticalmente e avança sobre o rio em diferentes direções, com o sentido da horizontalidade. Com mais de meio milhão de habitantes e uma população flutuante ponderável ela atualmente pode contestar a Oscar Niemeyer, que há poucos anos dizia não haver nada a notar na arquitetura de nossa cidade.

Oaumento do número de automóveis nas ruas e a ampliação do município em direção a zonas até então inabitadas foram temas expostos lado a lado, ou mesmo em conexão com a questão da arte nos textos do jornalista. Naquele período, o sistema artístico evoluiu congregando novos agentes, instituições e espaços expositivos. O Estado investia na organização da gestão cultural e patrocinava artistas em obras públicas. Em contrapartida, novos atores, como coletivos dedicados à arte social e autodidatas, questionavam padrões de valoração estabelecidos no circuito. Obino tematizava essa vitalidade no contexto da complexificação urbana, defendendo que uma cidade em crescimento precisava diversificar suas manifestações artísticas e espaços culturais e ampliar o intercâmbio com outros centros (Sirena, 2014).

Na primeira metade da década, percebemos que o colunista enfatizou a situação periférica de Porto Alegre quando comparada às capitais de referência - Rio de Janeiro e, principalmente São Paulo, a cidade brasileira que encarnava a representação da modernidade e cosmopolitismo. Depois de Porto Alegre, 
o município paulistano é o mais abordado no conjunto de textos, tendo sido citado 21 vezes (7\% do corpus) e festejado pelo arrojo e pelo evento das Bienais internacionais de arte. Porém, ao longo do decênio, a visão do Rio Grande do Sul como estado à margem da movimentação cultural no contexto nacional se dissipa. Uma gradativa efervescência cultural transparece e toma conta das Notas de Arte. O discurso de que "Porto Alegre está sendo remansoso e descansado fim de linha das principais metrópoles culturais do Brasil", e de que "o nosso intercâmbio com os grandes centros ressente-se da falta de amplo, real e fecundo vigor"8, é substituído pelo elogio à animação promovida por alguns agrupamentos de artistas e espaços expositivos alternativos.

Uma das principais transformações da década que fica evidente no conjunto de textos é a transferência de protagonismo de espaços adaptados - representados principalmente pelo Auditório do Correio do Povo e pela Casa das Molduras - para uma instituição oficial e coordenada pelo poder público, o Museu de Arte do Rio Grande do Sul (MARGS). O MARGS foi criado em 1954 e passou a ter uma sede própria apenas em 1957, quando se tornou o polo expositivo centralizador das artes visuais. Tal reorganização da esfera cultural se deu após a implantação da Divisão de Cultura da Secretaria de Educação e Cultura, em 1954.

Naquele período, a postura específica dos dirigentes buscava integrar a atuação das classes artísticas e intelectuais à ação de governo, avançando na institucionalização do campo cultural (Simon, 2005). Ainda assim, é inegável a importância de galerias como a Casa das Molduras, que abrigou 69 das exposições tematizadas nas Notas de Arte, sendo o local mais mencionado no corpus (21,9\% do total de textos referem-se a esta galeria), mantendo-se entre os dois principais espaços de referência da cobertura de Obino em todos os anos analisados separadamente.

O Auditório do Correio do Povo, situado no prédio do jornal e que, de 1947 a 1953, foi "o principal centro de gravitação das artes plásticas" ${ }^{\prime \prime}$, apareceu como segundo lugar mais recorrente, citado em 32 unidades analisadas (10,1\% do corpus). O Instituto Cultural Brasileiro Norte-Americano, criado em 1938 por intelectuais que tinham a intenção de aproximar o Brasil da língua e da cultura dos Estados Unidos, também funcionou como importante centro polarizador da cena artística e foi abordado 31 vezes (9,8\% do corpus). Uma quantidade semelhante de notas (31) trata de acontecimentos ocorridos em

8 Notas de Arte, 14 de dezembro de 1954.

9 Notas de Arte, 8 de dezembro de 1953. 
locais registrados apenas uma vez: são mostras em livrarias, vitrines de lojas e restaurantes, demonstrando que a rotina expositiva acontecia bem além dos espaços institucionais.

\section{Quem?}

Ao verificarmos quem eram os agentes tematizados nas Notas de Arte, constatamos que os artistas e criadores eram os protagonistas da coluna. Obino apresentava cada um deles de forma metódica e particular: sublinhava com veemência a proveniência do artista, local de nascimento ou moradia, o que reforça o apego pela dimensão do território e importância que a localização geográfica alcançava na sua escrita. As etnias eram elementos valorizados, salientados e utilizados como componentes biográficos. Predominam notas sobre mostras de artistas gaúchos e de estrangeiros radicados no Rio Grande do Sul: dos 239 textos sobre exposições ocorridas na cidade, 144 (60\%) são de artistas locais.

O número pequeno de artistas brasileiros provenientes de outros estados nas exposições em Porto Alegre (17\%), principalmente nas coletivas, reforça a falta de intercâmbio nacional na cidade, situação tão bem identificada e criticada por Obino. Ao mesmo tempo, a quantidade relativamente significativa de mostras internacionais (23\%) evidencia a possibilidade das galerias de fazer circular, no período pós-guerra, uma parcela da produção estrangeira, em especial a europeia, e, pela proximidade geográfica e cultural, a uruguaia.

Assim como o intercâmbio, o incentivo a novos agentes e distintas formas de expressão é sublinhado pelo colunista como condição básica para a ebulição do sistema artístico. Ainda que a notoriedade seja um valor fundamental do jornalismo e particularmente importante na configuração das Notas de Arte, existe um esforço de Obino em acompanhar a produção emergente no cenário local, elogiando as iniciativas dos jovens. Esse aspecto fica explícito quando são divulgadas coletivas em Porto Alegre: das 40 colunas sobre grupos de artistas locais, $19(47 \%)$ tratam de artistas iniciantes. Quando se fala de individuais eventos que, em geral, apresentam nomes que já trilham um caminho de consagração no circuito - essa proporção é diferente, mas ainda significativa: dos 104 textos sobre esse tipo de mostra, 25 (24\%) abordam artistas em início de carreira.

Contextualizado no jornal, esse comportamento ganha ainda mais relevância: o Correio do Povo era uma instituição com grande prestígio e ampla circulação. Para os iniciantes, a menção nas Notas de Arte, que tinha forte 
caráter de divulgação e considerável alcance de público, era fundamental e contribuía na tentativa da construção da sua notoriedade. Levando em conta a opção por evitar julgamentos aos artistas mais novos, manifesta em alguns textos, percebemos que o jornalista prezava pela proximidade com eles, tendo consciência do impacto que seu comentário poderia ter numa carreira incipiente e no mercado local de artes plásticas, que não era de fácil inserção.

Como dito anteriormente, Obino concedia especial atenção aos agrupamentos, dando relevo à importância do trabalho coletivo para superar as amarras com o passado. Por exemplo, ao falar do grupo Bode Preto, dedicado em especial ao cartunismo, o jornalista aproveita para alfinetar uma das tendências canônicas do período, a valorização da pintura acadêmica: "Os jovens lá estão desabafando seus ímpetos, pisando nos calos do bom-tom e do pinturejar acadêmico, não fazendo pintura bonita e nem cuidando de agradar. Esses bodes pretos são bem suscetíveis de espantarem as cabras brancas do academismo"10.

O tom de proximidade em relação ao leitor e aos personagens da coluna, construído por uma linguagem irônica e por vezes descontraída, era recorrente nas Notas de Arte não somente para falar sobre jovens. A relação de Obino com nomes consagrados também era próxima e demonstrada textualmente, permitindo a divulgação de informações "exclusivas" - característica típica do espaço da coluna. Os artistas mais recorrentes no conjunto de textos - José de Francesco (1895-1967), mencionado dez vezes; João Medeiros, tematizado cinco vezes; e Glênio Bianchetti (1928-2014), João Fahrion (1898-1970) e Vasco Prado (1914-1998), cada um abordado três vezes - eram referenciados a partir de atributos pessoais, marcas de personalidade, evidenciando a ligação subjetiva estabelecida entre as biografias e as obras.

\section{O quê?}

O caráter de cobertura cultural local predomina na coluna, valorizando o evento como elemento norteador do circuito artístico. As principais pautas das Notas de Arte eram justamente as exposições individuais na capital gaúcha: 164 unidades (52\% do corpus) abordam esse tipo de acontecimento. Ao lado das mostras coletivas, esses eventos motivaram a escrita de 239 textos (76\%), apontando o vínculo da coluna com o critério da atualidade. Depois das exposições, eventos institucionais e também coletivos como os Salões de Artes Plásticas, de Foto ou de Cerâmica ocorridos em Porto Alegre são as pautas mais

10 Notas de Arte, 23 de setembro de 1958. 
assíduas, sendo mencionadas em 15 colunas (5\%); e as bienais de São Paulo, que aparecem em terceiro lugar com 12 textos (4\%).

No caso das exposições individuais e coletivas, verifica-se a incidência da pintura como método de execução das obras em exposição nas galerias de Porto Alegre em 160 das unidades em análise (67\%), refletindo a hierarquização defendida pelo Instituto de Belas Artes (IBA), principal instituição do sistema de artes visuais no período. Tal técnica predominava como parâmetro de formação, ao lado da escultura. Contudo, o movimento em torno de outras linguagens também foi registrado: o desenho foi recorrente em 34 textos do corpus (14\%); gravura, em 31 (13\%); aquarela, em 23 (10\%); cerâmica, em 16 (7\%); arte aplicada em seis (2\%); monotipia, em três (1\%); crayon, em dois $(0,8 \%)$. Em conjunto, a representatividade desses métodos, que eram deixados em segundo plano pelo circuito, relaciona-se com a inserção de autodidatas no meio artístico e com a produção artística não institucional. É interessante observar que a gravura foi uma técnica representativa na década de 1950, principalmente devido aos movimentos dos Clubes de Gravura ${ }^{11}$, que a utilizavam vinculada à arte social.

Os Salões de Artes Plásticas do Rio Grande do Sul, por sua vez, mostraramse centrais na articulação do sistema artístico na capital. Eles contavam com júri específico de premiação, reforçando o papel consagratório do IBA. No período estudado, ganham destaque nas Notas de Arte os cinco salões oficiais, realizados pela instituição de ensino nos anos 1953, 1954, 1955, 1956 e 1958. Considerando os artistas premiados, nomes já estabelecidos no sistema local, havia uma forte primazia da arte acadêmica. Nesse sentido, a cobertura de Obino permitiu entrever tendências tanto da evolução como do declínio dessa instância oficial de formação e legitimação.

Já o acompanhamento das Bienais de São Paulo exemplifica o esforço do autor em atualizar seus leitores acerca das principais discussões que tomavam corpo em nível nacional. Mencionamos especialmente a segunda edição, ocorrida entre 1953 e 1954, à qual o colunista visitou e dedicou ampla atenção. $\mathrm{Na}$ abordagem do evento, explorou o registro e a descrição, apontando para algumas tendências, sendo o abstracionismo a principal delas.

Não é apenas pelo acompanhamento da agenda que o fator jornalístico da temporalidade se mostra estruturante tanto no texto de Obino como no jornalismo cultural em geral. As mortes e efemérides, tendo aparecido como mote para 12 textos (4\%), reforçam a ligação da escritura do colunista com o

11 Vasco Prado e Carlos Scliar formaram o Clube de Gravura de Porto Alegre, e Glênio Bianchetti, Glauco Rodrigues e Danúbio Gonçalves, o Clube de Gravura de Bagé. Vinculados ao realismo socialista, os artistas que formavam esses clubes viam a arte como possibilidade de transformação social. 
parâmetro da atualidade, já que elas eram lidas como eventos desencadeadores da revisão de legados artísticos reconhecidos. Esses ganchos jornalísticos atuam no processo de legitimação de sujeitos, formando narrativas que ajudam a construir o cânone. Em número menor, dez colunas (3\%) consistiram em reflexões sem fato temporal específico, denotando uma liberdade própria do espaço da coluna, que permite ao autor desenvolver o pensamento sem a necessidade do vínculo com o factual.

\section{Como?}

A coluna Notas de Arte foca-se na descrição, no serviço e na orientação sobre a agenda da cidade; no entanto, em fragmentos, apresenta-se também como lugar do julgamento e da opinião em leves pinceladas. Os valores artísticos, caros a Obino, emergem das entrelinhas, revelando certa ambiguidade de posicionamento. $O$ estímulo à renovação aparece apoiado numa perspectiva mais conservadora sobre a arte. Se a novidade é fator decisivo para o desenvolvimento do circuito, a defesa da "harmonia" expressiva é defendida com frequência. Para o autor, a arte não deveria estimular fraturas na ordem social, o que o levou a criticar a interferência de posições políticas na produção de artistas, especificamente as do pensamento de viés marxista. Por outro lado, a arte social produzida no Rio Grande do Sul, por meio dos nomes reunidos em torno dos clubes de gravura, era considerada em sua riqueza e importância.

Contextualizando a coluna no sistema artístico de Porto Alegre dos anos 1950, é possível perceber uma aproximação das ideias do colunista com a posição das principais instituições frente às tendências inovadoras. Naquela época, o Instituto de Belas Artes tendia ao conservadorismo (Krawczyk, 2005), apesar de, com o passar dos anos, ter-se aberto a experiências modernistas. A formação de Obino, ligada aos valores da arte clássica, sintonizava-se com noções dominantes sobre cultura, o que explica sua reserva em relação aos artistas transgressores que ganhavam visibilidade principalmente nos grandes centros como São Paulo. Porém, o incentivo ao intercâmbio, atitude coerente com a exaltação contínua ao movimento da grande cidade, é a marca que prevalece no conjunto de textos analisados.

Apesar da desconfiança, as novidades do circuito tinham espaço garantido na coluna de Obino. Tanto que o debate sobre o abstracionismo provocado no centro do país era assimilado pelas Notas de Arte como movimento a ser considerado e contextualizado pela crítica. Isso acontecia mesmo que o 
figurativismo fosse a expressão preferida não apenas das principais instâncias do sistema artístico no Rio Grande do Sul, mas também do próprio colunista.

Uma das discussões do período girou em torno da superação do academicismo. Essa questão apareceu no corpus associada diretamente à configuração da cidade moderna. Ao se urbanizar, Porto Alegre abria espaço para diferentes expressões e demandava por elas. Uma coluna de 1953 deixa clara a ligação estabelecida entre a urbe em transformação e artistas em circulação conectados com as temporalidades de sua época:

Já estamos longe do tempo em que o academismo tinha uma praça forte em Porto Alegre, com a lonjura dos grandes centros de renovação, a guerra, a falta de intercâmbio, a ausência de fermentação e a estagnação das rotinas. A cidade não construía e as ruas não tinham quase tráfego. Foi só terminar a pugna e a cidade despertou. Recomeçou a vida normal e o RS, retardado entre os mais em Arquitetura e Pintura, recebeu o impacto da renovação, com o intercâmbio entre Rio-São Paulo e Montevidéu-Buenos Aires. A nossa gente recomeçou a viajar por vários continentes, fundaramse inúmeras organizações artísticas e recebemos personalidades e sugestões fecundas ${ }^{12}$.

Por meio dessas palavras, retornamos à importância dada à configuração mutante da cidade que surge como elemento conformador da produção artística, assim como das demandas nesse meio - inclusive em termos de novos valores.

\section{Considerações finais}

A elaboração de relatos vívidos sobre a cultura no contexto urbano foi um dos feitos dos homens da imprensa ao longo do século XX, permitindo aos leitores-pesquisadores contemporâneos visualizar uma cartografia sensível das cidades e da cultura, marcada pela subjetividade. Aldo Obino foi um desses homens de imprensa, construiu uma narrativa marcada pelo afeto, pertencimento e pelo fascínio da cidade em transformação. Seu discurso acompanhava o espírito da época, voltado à aceleração da vida urbana, encarnada nos centros das metrópoles. Guiou detalhadamente o leitor pela geografia do circuito artístico a partir de parâmetros de leitura típicos do fazer jornalístico. A proximidade foi seu principal critério, dando a conhecer espaços, agentes e valores do sistema das artes de Porto Alegre.

12 Notas de Arte, 8 de dezembro de 1953. 
Como mediador, afiançou o valor da notoriedade, reforçou a credibilidade de certos artistas, sem descuidar da divulgação dos novos. $O$ evento, marcador temporal da atualidade, constituiu outro eixo estruturante não apenas da coluna como do próprio funcionamento do sistema artístico. Utilizando o espaço autoral para avaliar a produção artística e orientar a fruição, evidenciou debates e posicionamentos em voga no período. Reproduziu, assim, um comportamento típico do jornalismo cultural na sua condição de orientador, de informar e avaliar.

A ideia de Mouillaud (2002), que comparou as notícias dispostas no jornal aos elementos de um mapa, é também aplicável à coluna de Obino - podemos lê-la a partir de seu caráter cartográfico. A coluna Notas de Arte constitui um mapa de lugares, sujeitos, eventos e valores. Pela sua narrativa, é possível avistar Porto Alegre escrita desde um ponto de vista particular. Nos fragmentos, vigora o ambiente em mutação, atravessado pelo ímpeto e pelo ritmo de novos agentes em demanda por diversas formas de expressão nos anos 1950. É o centro que tanto consagra como tensiona valores conservadores, pontuado pelo ritmo espaçado, mas regular, dos fluxos que vem de fora. É a capital que parece ter suas feições transformadas pela modernidade, mas cuja arte ainda necessita sintonizar-se com essa temporalidade. É também a cidade que padece por sua posição geográfica e cultural periférica, configurando-se em alguns momentos como território à margem do Brasil.

\section{Referências}

ALMEIDA. Armando. Lembranças e envolvimento pessoal - Anos 70, os últimos tempos no foyer. In: GOMES, Paulo; GRECCO, Vera (Org.). MARGS 50 Anos - Memória do Museu. Porto Alegre: MARGS: 2005.

BARDIN, Laurence. Análise de Conteúdo. Lisboa: Edições 70, 1977.

BAUER, Martin. Análise de conteúdo clássica: uma revisão. In: BAUER, Martin; GASKELL, George. Pesquisa qualitativa com texto, imagem e som: um manual prático. Petrópolis, RJ: Vozes, 2002.

BURKE, Peter. Uma história social do conhecimento: de Gutenberg a Diderot. Rio de Janeiro: Jorge Zahar, 2003.

FRANCISCATO, Carlos Eduardo. A fabricação do presente: como o jornalismo reformulou a experiência do tempo nas sociedades ocidentais. São Cristóvão: 
Editora UFS; Aracaju: Fundação Oviêdo Teixeira, 2005.

GADINI, Sérgio. Interesses cruzados: a produção da cultura no jornalismo brasileiro. São Paulo: Paulus, 2009.

GOLIN, Cida; KELLER, Sara; CARDOSO, Everton. A cidade no jornalismo cultural: uma perspectiva de Porto Alegre na cobertura do Diário do Sul (1986-1988). Brazilian Journalism Research, SBPjor, v. 8, n. 1, p. 53-69, 2012.

GOLIN, Cida; CARDOSO, Everton; SIRENA, Mariana. Pesquisas sobre jornalismo e sistema de cultura: metodologia para construção de panorâmicas, índices e padrões comparativos entre periódicos. In: JORGE, Thaís de Mendonça (org.). 0 desafio de apliar a análise de conteúdo no jornalismo digital. Brasília: Insular, 2014.

KRAWCZYK, Flávio. Roteiro do descompasso e da inovação: os salões de artes plásticas em Porto Alegre - 1925/1971. In: BULHÕES, Maria Amélia (org.). Memória em Caleidoscópio: artes visuais no RS. Porto Alegre: Editora da UFRGS, 2005.

LEAL, Bruno Souza; ANTUNES, Elton. O acontecimento como conteúdo: limites e implicações de uma metodologia. In: LEAL, Bruno; ANTUNES, Elton; VAZ, Paulo Bernardo. (Org.) Jornalismo e acontecimento: percursos metodológicos. v.2. Florianópolis: Insular, 2011.

MELO, José Marques de. Jornalismo opinativo: gêneros opinativos no jornalismo brasileiro. Campos do Jordão: Mantiqueira, 2003.

MONTEIRO, Charles. Imagens da cidade nos anos 1950 na imprensa: Porto Alegre. In: SIMPÓSIO NACIONAL DE HISTÓRIA, 23, 2005, Londrina. Anais... do XXIII Simpósio Nacional de História - História: guerra e paz. Londrina: ANPUH, 2005.

MOUILLAUD, Maurice. Crítica do acontecimento ou o fato em questão. In: PORTO, S. (org). O jornal: da forma ao sentido. Brasília, editora UnB, 2002.

OBINO, Aldo. Aldo Obino: notas de arte. Organização: Cida Golin. Porto Alegre: MARGS; Nova Prova; Caxias do Sul: EDUCS, 2002.

PARK, Robert Ezra. A cidade: sugestões para a investigação do comportamento humano no meio urbano. In: VELHO, Otávio Guilherme (org.). O fenômeno urbano. Rio de Janeiro: Zahar, 1973.

RIBEIRO, Ana. Imprensa e história no Rio de Janeiro dos anos 1950. Rio de Janeiro: E-papers, 2007.

SIMON, Círio. A instituição MARGS. In: GOMES, Paulo; GRECCO, Vera (Org.). MARGS 50 Anos - Memória do Museu. MARGS: Porto Alegre, 2005.

SIRENA, Mariana. O circuito artístico de Porto Alegre na década de 1950 a partir do jornalismo: análise da coluna Notas de Arte, de Aldo Obino, no Correio do Povo. 2014. Dissertação (Mestrado em Comunicação e Informação) - Programa 
de Pós-Graduação em Comunicação e Informação, Universidade Federal do Rio Grande do Sul, Porto Alegre, 2014.

SÜSSEKIND, Flora. Papéis colados. Rio de Janeiro: Editora UFRJ, 2002.

Recebido em: 14 agosto 2014

Aceito em: 26 novembro 2014

Endereço das autoras:

Cida Golin <golin.costa@ufrgs.br>

Mariana Sirena <sirena.mariana@gmail.com>

Programa de Pós-Graduação em Comunicação e Informação

Universidade Federal do Rio Grande do Sul

Rua Ramiro Barcelos 2705 - $2^{\circ}$.andar - Santana

CEP: 90.035-007 - Porto Alegre - RS - Brasil

Telefone: (51) 3308.5116 